\title{
La necesaria transformación de los géneros: del papel al ciberperiodismo
}

\author{
Susana Domínguez QuinTaS \\ Universidad de Vigo \\ squintas@uvigo.es \\ Montserrat Doval Avendaño \\ Universidad de Vigo \\ montse.doval@uvigo.es
}

\section{Resumen}

En 1999 el profesor Cantavella publicaba en "Estudios sobre el Mensaje Periodístico" una interesante reflexión sobre la necesidad de cambiar los géneros periodísticos para adaptarlos a las nuevas tendencias. La información de actualidad propia del nuevo entorno digital, en el que las redes sociales tienen un peso específico, debe tener en cuenta las diferentes posibilidades narrativas para el diseño y la construcción de nuevas formas expresivas a través de una necesaria revisión de los géneros periodísticos.

Palabras Clave: Ciberperiodismo, cibergéneros

\section{The necessary transformation of genres: from paper to online journalism}

\begin{abstract}
In 1999 Cantavella published in "Estudios sobre el Mensaje Periodístico" an interesting reflection on the need to change the journalistic genres to suit the new trends. Breaking news, well suited for the new digital environment, in which social networks have a significant weight, must take into account the different narrative possibilities for the design and construction of new forms of expression through a necessary revision of journalistic genres.
\end{abstract}

Key Words: online journalism, online genres

\section{Referencia normalizada:}

Domínguez Quintas, S. y Doval Avendaño, M. (2013) La necesaria transformación de los géneros del papel al ciberperiodismo. Historia y Comunicación Social. Vol. 18. $\mathrm{N}^{\mathrm{o}}$ Especial Diciembre. Págs. 187-197.

Sumario: 1. Introducción. 2. La necesaria evolución del periodismo. 2.1. La importancia de la documentación. 2.2 Mayor control de la calidad de los contenidos. 2.3 Un nuevo profesional de la información. 2.4 La necesidad de diferenciar contenidos. 2.5 La necesaria transformación de los géneros: del papel a la web. 2.5.1. La información o noticia. 2.5.2 El reportaje. 2.5.3. La entrevista. 2.5.4. Del editorial al suelto y de la columna personal al blog. 3. Conclusión. 4. Bibliografía 


\title{
1. Introducción
}

Al final del siglo XX la red planteaba ya un cambio en el panorama informativo por el uso de nuevas herramientas, se iniciaba un largo recorrido para descubrir las posibilidades de un nuevo escenario digital y en el que el mundo científico se preocupaba por buscar el perfil más adecuado para el nuevo profesional del periodismo que, necesariamente, debía salir de nuestras universidades, Cantavella decía que "lo que más nos afecta es la configuración de los textos que se presentan en los medios de comunicación escritos" (Cantavella, 1999: 64).

Hace ya más de una década que el profesor Juan Cantavella publicaba en la revista Estudios sobre el Mensaje Periodístico un texto en el que proponía una interesante reflexión: la necesaria evolución de los géneros periodísticos. Cantavella cerraba su texto diciendo:

\begin{abstract}
"Estas son a grandes rasgos las líneas de futuro que vemos desprenderse del pasado y presente de los géneros periodísticos y que desearíamos que se pusieran al servicio de ese público masivo que encuentra en ellos conocimiento, apoyo, distracción y ayuda para situarse en el mundo. En la medida en que los periodistas no se limiten a proveer de información en bruto a las redes, sino que seleccionen los hechos, relaten fidedignamente lo acontecido y lo pongan a disposición de todos los lectores por medio de un lenguaje apropiado y a través de los géneros que convengan a esos fines, continuará existiendo el periodismo. Aunque el producto final se parezca poco al que disfrutamos ahora" (Cantavella, 1999: 74).
\end{abstract}

Las características que la red ofrece para la difusión de contenidos periodísticos: un soporte multimedia, la narrativa hipertextual, y la posibilidad de interactuar (Armañazas et al., 1996) así como la continua actualización de los contenidos, nos permitían pensar en un futuro no muy lejano en el que el mensaje digital tenía que tener unas características propias, en el que el uso de un "lenguaje múltiple" (Edo, 2001: 86) tendría que determinar la existencia de una nueva manera de contar, de narrar y, por lo tanto, tendríamos que pensar en un nuevo modo de construir los mensajes periodísticos.

En ese momento tal reflexión era muy necesaria, años antes Peltzer ya advertía sobre la necesidad de una nueva actualización de los géneros periodísticos que consideraba "imprescindible para entender toda la información en todas sus formas actuales" (Peltzer, 1991: 86) en ese momento en el que la revolución digital llamaba a la puerta.

Es gratificante comprobar cómo lo que se planteaba en 1999 como una reflexión perfectamente razonada por el devenir de la historia más reciente, transcurridos los años se ha convertido en una realidad que, como él perfectamente vaticinaba, sigue sometida a una continua evolución.

Cuando unos dos años antes Martínez Albertos en El ocaso del periodismo vaticina que la muerte de los periódicos impresos sería una realidad no muy lejana (pronosticaba el año 2020) y asegura, como bien recoge Cantavellla (1999: 66), que 
"el periodismo se está convirtiendo en un técnica social desechable por innecesaria" (Martínez Albertos, 1997: 51) lo que conseguía era llamar la atención sobre la imperante necesidad de hacer otro tipo de periodismo, una regeneración necesaria por la irrupción de la red en el mundo de la comunicación de actualidad.

\section{La necesaria evolución del periodismo}

Los caminos emprendidos para la regeneración del periodismo son muchos y muchas investigaciones ya han dado sus frutos, pero lo cierto es que todavía hoy hay terrenos que no se han abordado y es un ejercicio necesario. Muchos de los que nos hemos dedicado a la docencia desde hace ya años hemos defendido la necesaria y enriquecedora evolución del periodismo y hemos compartido la visión de unos géneros cambiantes, no por capricho, sino por la adaptación a su entorno, a su contexto. Así lo han señalado, por ejemplo, en la revista valenciana Comunicación y Estudios Universitarios Francisco Sánchez y Fernando López Pan al afirmar que "Los géneros son instituciones vivas que evolucionan para ajustarse a las funciones propias de la actividad a la que sirven” (Sánchez y López Pan, 1998: 18); y también Echevarría Llombart al asegurar que los géneros son "un sistema de referencias que se modifican y evolucionan continuamente. No son un esquema rígido y único que limita los recursos expresivos y la capacidad creativa de los periodistas" (Echevarría Llombart, 1998: 10).

\subsection{La importancia de la documentación}

“La documentación es una elemento que estará cada vez más presente en las páginas informativas. La abundancia de noticias — sobre todo radiofónicas y televisivas- - es tan sobrecogedora que el lector buscará en los medios impresos una valoración y una complementariedad de lo que se le ofrece. No basta con situarle frente a la complejidad de un problema los primeros días en que estalla un determinado conflicto, sino que es necesario volver una y otra vez cuando se trata de una situación que se prolonga en el tiempo, con el fin de aportar elementos de utilidad para el lectores que se incorporan o para los olvidadizos, que son los más" (Cantavella, 1999: 70).

La rapidez en la transmisión de la información más actualizada que antes nos proporcionaba la radio con sus boletines informativos, nos llega ahora a través de la red, bien gracias a las suscripciones a servicios informativos a través de dispositivos móviles, o bien con el simple acceso a la página web de un medio cualquiera. Sin lugar a duda esos momentos informativos son diferentes, y el usuario en el momento que accede por segunda vez a una información pedirá algo más que en su primer acceso. Es por eso que la información debe de ir completándose en función de la evolución de los propios acontecimientos y en función de la relevancia de los mismos. Cuanto más permanece una noticia en el medio como consecuencia de su interés relevante, más completa debe ser la información sobre ese hecho. Los diarios online deben recurrir, 
para la satisfacción de los usuarios y porque su entorno lo permite, al uso de enlaces, tanto internos como externos, que relacionan los hechos con otros acontecidos con anterioridad, con los protagonistas, con el análisis de expertos, con las propias fuentes de información, etc.

\subsection{Mayor control de la calidad de los contenidos}

"Todo esto llevará a un control más estricto de los textos periodísticos, tanto para que el relato se halle más ajustado a los hechos como para que resplandezca la calidad en el lenguaje y en la presentación. La eficacia comunicativa no está reñida con la competencia redaccional y ésta será muy tenida en cuenta, porque la palabra escrita es precisamente lo que distingue a los medios impresos, cuya supervivencia se intentará mantener, frente a la instantaneidad, acción abarcadora y a la fuerza de las imágenes presente en los otros medios. Se practicará menos el periodismo de declaraciones, se atenderá con menor afán a las polémicas entre políticos y partidos y no se prestará tanta atención a los núcleos poco productivos (repetir lo sabido, crear ambiente ante las confrontaciones, glosar lo que los artistas producen y que desean explicar a toda costa)". (Cantavella, 1999: 71)

Esta forma de hacer periodismo que presenta el profesor Cantavella sería la más adecuada para intentar recuperar para el periodismo escrito los mínimos de calidad a los que ya no nos tienen acostumbrados. Muy a nuestro pesar esa prensa más sensacionalista, de menor calidad, es la que sigue teniendo más presencia. La celeridad en la transmisión de los acontecimientos sigue siendo una premisa básica en el desarrollo de los quehaceres de los profesionales del ciberperiodismo más preocupados por la continua actualización de los contenidos de sus páginas, que por la calidad de los textos. La manera de corregir esta tendencia puede pasar por diferenciar los contenidos, o mejor dicho el modo de presentar los contenidos, en función del soporte: la rápida actualización y el relato continuado y sucesivo de los hechos más la participación activa de los lectores, y el análisis reflexivo y concienzudo de lo sucedido en el papel.

\subsection{Un nuevo profesional de la información}

"Es posible que por fin el periodismo atienda menos a las convocatorias interesadas de aquellas fuentes que no tienen otra función que glosar los éxitos de sus respectivos jefes, empresas o instituciones, en beneficio de una auténtica investigación y profundización de las cuestiones que resultan de interés masivo (o sea, menos atención a lo que Boorstin denomina «pseudo-acontecimientos). Ello llevará a que todo el periódico se oriente en una línea de no atender únicamente a superficialidades, sino que se intentará llegar al fondo de las cuestiones suscitadas. Es posible que se produzca una división en el trabajo redaccional, con unos profesionales que se sienten más seguros y sueltos en la tarea de inquirir y reunir datos, mientras que otros tendrán como misión — porque sus cualidades les llevan en esa dirección- el escribir un relato con el material que aportan sus compañeros. Habría, pues, investigadores por una parte y redactores propiamente dichos" (Cantavella, 1999: 71-72).

Esta propuesta de Cantavella es realmente atractiva, pero por el crítico momento por el que atraviesan las empresas editoras de la prensa no creemos que pueda conver- 
tirse en una realidad. Cada vez se demanda más al profesional capaz de hacer de todo menos ser periodista, de todo menos redactar con fluidez textos claros y concisos, con los que transmitir la realidad de los acontecimientos guiados por una ética de la verdad (Giménez Armentia, 2005: 91-103). La necesaria regeneración de los profesionales de los medios a la que hace referencia Salaverría (2010: 236-249) está más cerca de la realidad que la propuesta de Cantavella, los años transcurridos entre una y otra nos dejan ver que la adecuada formación de los profesionales de ciberperiodismo no es todavía una realidad.

\title{
2.4 La necesidad de diferenciar contenidos
}

\begin{abstract}
"Los periódicos de prestigio son los únicos que tienen sentido en el futuro, puesto que los sensacionalistas llegará un momento en que no podrán competir con el espectáculo que la televisión estará ofreciendo a todas horas. ¿Cómo se podrá atraer a los lectores con un entretenimiento mayor, cuando en la televisión se encontrarán los espectadores con una permanente incitación y un salto continuo de un tema a otro, de una diversión a otra, con espacios impactantes, pero triviales y que no exigen pensar?" (Cantavella, 1999: 72)
\end{abstract}

Otro fallo en la previsión de futuro de Cantavella. Las portadas de los cibermedios se llenan de contenidos de muy diferente naturaleza: desde cuestiones social y políticamente relevantes, de interés público en términos de Ladevéze, hasta los que son triviales, banales, de interés del público por lo que de relevantes tienen sus protagonistas. A este deseo del profesor Cantavella todavía no hemos llegado, pero es cuestión de tiempo. En las páginas de nuestros diarios (en papel u online) todavía conviven las informaciones de calidad y las sensacionalistas, pero lo lógico es que, con el tiempo, las empresas sean conscientes del uso diferencial del consumo que se puede hacer de uno y otro producto. Es por ello que debemos buscar las fórmulas más adecuadas para llegar a todos los públicos con un producto diferenciado en cuanto a la elección de temas, estructura y enfoque. Y es aquí donde residirá el valor diferencial del periodismo escrito.

2.5 La transformación de los géneros

\subsubsection{La información o noticia}

La información básica sobre un acontecimiento, la noticia, llega al público gracias a los boletines de radio y televisión (Grijelmo, 1998: 39) y gracias a la continua actualización de los contenidos en la red. La necesidad de ofrecer un producto diferenciador a un público más exigente que el de la radio y la televisión nos haga pensar que la alternativa en ofrecer un producto de valor está en la interpretación.

"La interpretación irá tomando mayor vuelo en los periódicos a expensas de la información pura y simple. Eso llevará a que los géneros informativos no se dirijan tanto a contar los hechos como a explicarlos. Habrá mayor número de reportajes interpretativos, así como análisis y columnas de este tipo" (Cantavella, 1999: 72). 
Es cierto que en los últimos años hemos sido testigos de cómo la pura y escueta información dejaba paso a la interpretación en los diarios nacionales, pero también es cierto que esta labor interpretativa del periodista no se ha llevado a cabo, en muchas ocasiones, de la manera más adecuada. Si bien la apreciación de Grijelmo es correcta, y los primeros contactos que la audiencia tenía sobre los acontecimientos era la radio y la televisión, esa realidad con la expansión de los cibermedios ha cambiado y el primer contacto que un amplio número de la comunidad tiene es a través de los cibermedios. Las portadas que los usuarios de la red abren en sus ordenadores les llevan al acceso directo de la última hora, un contenido textual que se puede actualizar constantemente, de manera que el hecho noticioso va ganando valor informativo gradualmente y puede ir acompañado de imágenes, videos y un amplio número de herramientas que fomentan la participación.

"La noticia aislada tendrá menos presencia de la que ahora se percibe y dejará paso a esa clase de textos para los que todavía no hemos encontrado un nombre que los unifique en las redacciones (informaciones, noticia compleja...). La noticia suelta quedará quintaesenciada en los breves o presentada en una doble dirección: unas veces será tratada con alarde creativo o la veremos reportajeada, algo que ya venimos observando en algunos medios. En este afán por enfocar los problemas en su complejidad, «los medios se ocupan más de procesos que de acontecimientos, ya no abandonan totalmente un tema después de haberle dedicado durante algunos días una atención exagerada» (Bertrand, p. 21)" (Cantavella, 1999: 72-73).

Lo aquí expuesto es la realidad a la que hemos llegado en el ciberperiodismo, las noticia breve es el primer paso en ese proceso de aprendizaje de la actualidad que muchos de los lectores demandan o buscan. Gracias a las características esenciales y propias del ciberperiodismo: la hipertextualidad, la multimedialidad, y la interactividad; el usuario puede tener una visión completa de los acontecimientos que él mismo reconstruye, gracias al uso de un lenguaje multimedia (Salaverría, 2004) o lenguaje múltiple $^{1}$ (Edo, 2003: 35). Una realidad reconstruida gracias a la elaboración de un mensaje periodístico determinado por la actualización constante o continuada de la información, con una capacidad expresiva mayor en la que se combina las características de la prensa escrita (texto y elementos iconográficos fijos), con las de la radio (sonido) y con las de la televisión (imágenes y gráficos en movimiento): una información multimedia y con una gran profundidad en el contenido conseguido gracias al uso de una narrativa hipertextual. Esto supone la construcción de un discurso periodístico nuevo que se inicia en el momento en el que irrumpe el primer título que informa sobre lo que acaba de suceder, hasta la elaboración del último texto relacionado con lo acontecido. Tras la simple comunicación de los hechos noticiosos, y gracias al uso de enlaces, la información irá creciendo en extensión al mismo tiempo que el estilo informativo inicial se encamina hacia la interpretación de los hechos y el análisis de la actualidad.

\subsubsection{El reportaje}

"El reportaje no ha logrado manifestar todas sus potencialidades todavía. Es mucho mayor el provecho que se le puede sacar, por lo que estamos seguros de que 
el desarrollo irá acompasado a los descubrimientos y avances que se vayan efectuando. Tendrá menos sentido el reportaje vacío de contenidos y por tanto de escaso atractivo, que a veces todavía se practica, para dejar paso al que se le ve dotado de solidez, cargado de datos ciertos y de opiniones solventes, que informa, explica y, consecuentemente con ello, orienta a la opinión" (Cantavella, 1999: 73).

Es una realidad, pero no se cultiva en exceso. Queda mucho camino por recorrer, y debemos intentar establecer qué ciberperiodismo queremos hacer. Si el ideal es, como afirma Cantavella, mejorar y redactar textos más elaborados, lo cierto es que el tipo de consumidor de los cibermedios demanda otra cosa. El informe norteamericano titulado "Magazines and their web sites" (Navasky \& Lerner, 2010), publicado en Columbia Journalism Review, dice que la edición y las fuentes se cuidan menos en internet que en la versión impresa, debido a la velocidad en la elaboración y en el consumo del nuevo producto periodístico.

\subsubsection{La entrevista}

La entrevista, con todas sus variantes, es uno de los géneros más atractivos para la red, y aunque Cantavella veía que con el ciberperiodismo "Se perderá ese afán de entrevistar a troche y moche, con periodistas que disparan sus preguntas al aire y recogen tan sólo declaraciones interesadas o improductivas" (Cantavella, 1999: 74) lo cierto es que el periodismo de declaraciones ha ido ganando terreno al periodismo de investigación, y por mucho que nos pese, eso ha llenado los diarios de unos textos que atraen al lector de hoy en día; ese lector al que le gusta el consumo rápido de la información y que además se siente más formado y capaz de acercarse a determinados personajes con una capacidad crítica. Pero no es a este periodismo de declaraciones al que nos queremos referir al hablar de la entrevista, no nos fijamos en esos textos construidos, la mayoría de la veces, solo gracias a una declaración llamativa de un personaje relevante que en la mayoría de las ocasiones está interesado en salir en los medios. La entrevista más enriquecedora es la que nos acerca a un personaje que nos interesa por lo que es y al que el periodista se acerca tras un profundo trabajo de preparación para el encuentro: es la diferencia entre el texto construido tras una rueda de prensa o conferencia determinada por el personaje y el texto construido tras un acuerdo pactado entre las partes (más reflexivo y elaborado). La entrevista pactada tiene una caducidad relativa, es ese texto que no requiere su publicación con urgencia, porque no se le relaciona con un acontecimiento reciente concreto y por tanto su publicación no tiene un tiempo. Algo parecido sucede con dos de sus subgéneros más atractivos: el perfil y la semblanza. Mientras en el primero se limita a plasmar en un texto una selección de datos fruto de una acertada labor de documentación que nos acercan a determinado personaje (que debe estar de actualidad y que suele acercarnos a la figura relevante del la información del día); el segundo, la semblanza, requiere una labor de interpretación del personaje a través del encuentro o trato directo entre quien escribe y el personaje, que permite que el lector aprehenda su personalidad, con un texto estilísticamente mucho más atractivo y la mayoría de las veces elaborado sin una justificación informativa que sin embargo interesa a los cibermedios por su agilidad en el consumo. Pero es la entrevista online o encuentro digital el que mayor atrac- 
tivo tiene para ese usuario consumidor de la información de hoy. El planteamiento es atractivo: acercar determinada personalidad a un público activo que le pregunta sin veto, por lo menos aparente, a ese personaje; pero los inconvenientes no son pocos: preguntas, la mayoría de las veces, largas y extensas que sin criterio ni orden se plantean a un interlocutor cercano en cuanto a trato, pero lejano en conocimiento. La figura del periodista intermediario, formado e informado sobre el personaje que está presente en las entrevistas literarias o de creación (Quesada y Fratinni, 1994: 303) desaparece y en su lugar tenemos a un número incierto de personas que en muchas ocasiones bombardean con preguntas largas, sin orden ni criterio, y que tienen una rápida respuesta. La ausencia de una reelaboración del texto conseguido, la inexistencia de una recreación del ambiente omitido y la desaparición de una estructura textual prefijada y reflexiva, hacen que la calidad del texto no alcance unas cotas mínimas de interés por lo que se dice. El valor de este nuevo modo de entrevistar reside únicamente en la posibilidad que se da a los usuarios de poder preguntar a un personaje que de otro modo sería inalcanzable.

\subsubsection{Del editorial al suelto y de la columna personal al blog}

En los cibermedios la función editorial no varía de la prensa tradicional o papel, suelen ser los mismos textos, pero es una realidad que el artículo editorial ha perdido el interés del público y se ha visto reducido (con la excepción de la prensa de prestigio) por el suelto, que por su extensión, esquematismo, contundencia o enfoque superficial gusta más a quien hace un consumo rápido de los contenidos.

Salvo esta transformación del editorial en suelto (Cantavella, 1999: 74) el resto de los géneros propios del estilo editorial siguen intactos, pero también es cierto que han aparecido nuevas formas de expresión individual de la opinión sobre determinados acontecimientos que no son posibles en el periodismo tradicional: el caso de los blogs, convertidos en espacios abiertos a los comentarios de los columnistas de antes y hoy blogueros. Lo mismo que los diarios tradicionales han cultivado y cuidado la labor persuasiva de sus columnistas, los cibermedios han conseguido tener en sus páginas blogs de colaboradores que con una mirada crítica analizan la actualidad política, económica, cultural, deportiva, etc. Es la forma de poner en primera persona el comentario sobre la actualidad con un enfoque personal y único, con el que el usuario se identifica y que ya mostró con acierto Cantavella al decir:

"La columna personal ha sido un género que ha tomado un incremento notabilísimo en los últimos tiempos, enfocada hacia la opinión. Pero se ha cultivado muchísimo menos la que lleva una carga informativa preponderante, expuesta desde la subjetividad del firmante. Es hora de incidir más en esta dirección que puede resultar muy fructífera y que genera una dependencia respecto al autor" (Cantavella, 1999: 73).

Las entradas de estos nuevos columnistas suelen ser breves y tremendamente subjetivas y esa libertad expresiva literaria y ese poder sugestivo sobre el asiduo lector que además ahora puede participar con sus comentarios sólo puede alcanzarse con otro género: la crónica. 
En los blogs y en las crónicas deberíamos encontrar esos rasgos que apuntaba Cantavella como representativos del articulismo moderno.

"En el articulismo se manifiesta una inclinación, que será más profunda en adelante, respecto a la solidez de los contenidos doctrinales, muy por encima de la carga literaria, humorística o costumbrista que se apreciaba en otras épocas. Esta solidez no estará reñida con la gracia o la habilidad con que se expresan las ideas que se desean transmitir o con el relato de las experiencias personales que sirven de envoltura para el pensamiento" (Cantavella, 1999: 74).

\section{Conclusión}

Las cabeceras tradicionales han apostado por un periodismo de inmediatez en el entorno online, compitiendo con los medios que habitualmente daban la información de última hora en la etapa previa a Internet, sobre todo, la radio. Esto ha incrementado el recurso al periodismo de declaraciones, sin valor añadido para la audiencia y ha modificado, por ejemplo, la estructura de la entrevista en su modalidad de encuentro o charla online.

Al contrario de lo previsto por Cantavella, los géneros de interpretación y el trabajo de contextualización sufren un retroceso en las versiones online de los medios.

La información de actualidad propia del nuevo entorno digital debe tener en cuenta las diferentes posibilidades narrativas para el diseño y la construcción de nuevas formas expresivas a través de una revisión de los géneros periodísticos. Pero lo cierto es que, a pesar de ser conscientes de los cambios, seguimos buscando el camino.

\section{Bibliografía}

ARMAÑAZAS, Emy, DÍAZ NOCI, Javier y MESO, Koldo (1996): El periodismo electrónico. Información y servicios multimedia en la era del ciberespacio, Ariel, Barcelona.

CANTAVELLA, J. (1999): "Textos dinámicos y atractivos para un periodismo cambiante. Aproximación a las tendencias de futuro en los géneros periodísticos", en Estudios sobre el Mensaje Periodístico, 5, 63-75.

EDO, C. (2001): "El lenguaje periodístico en la red: del texto al hipertexto y del multimedia al hipermedia" en Estudios sobre el Mensaje Periodístico, $\mathrm{n}^{\circ}$ 7, 79-94.

EDO, Concha (2003): Periodismo informativo e interpretativo. El impacto de Internet en la noticia, las fuentes y los géneros, Comunicación Social, Ediciones y Publicaciones, Sevilla.

ECHEVARRÍA LLOMBART, B. (1998): "Por qué hablar hoy de géneros periodísticos", en Comunicación y Estudios Universitarios, n 8, 9-14. 
GIMÉNEZ ARMENTIA, P. (2005): "La objetividad, un debate inacabado", en Comunicación y Hombre, 1.

GRIJELMO, A. (1998): "La presencia del periodista en los géneros", en Comunicación y Estudios Universitarios, 8, 37-50

MARTÍNEZ ALBERTOS, José Luis (1997): El ocaso del periodismo, CIMS, Barcelona.

PELTZER, Gonzalo (1991): Periodismo iconográfico, Ediciones Rialp, Madrid.

QUESADA, Montserrat y FRATTINI, Eric (1994): La entrevista. El arte y la ciencia, Eudema, Madrid.

SALAVERRÍA, R. (2010): “¿Ciberperiodismo sin periodistas? Diez ideas para la regeneración de los profesionales de los medios digitales", en CAMPOS FREIRE (coord.): El cambio mediático, Zamora, Comunicación Social Ediciones y Publicaciones: $236-249$.

SÁNCHEZ, F. y LÓPEZ PAN, F. (1998): "Tipologías de géneros periodísticos en España", en Comunicación y Estudios Universitarios, 8: 15-36.

Artículos en publicaciones web

NAVASKY, V. (2010): "Magazines and Their Web Sites. A Columbia Journalism Review survey and report", en Columbia Journalism Review: http://www.cjr.org/ resources/magazines_and_their_websites/ [13 de julio de 2013]

SALAVERRÍA, R. (2004): “Diseñando el lenguaje para el ciberperiodismo", en Chasqui, 86, 2004: http://chasqui.comunica.org/86/salaverria86.htm [3 de marzo de 2013]

\section{Notas}

1 Concha Edo se refiere al lenguaje múltiple como aquel que aporta la posibilidad de escoger el formato más adecuado para cada uno de los relatos, análisis o comentarios de actualidad.

\section{Las autoras}

Susana Domínguez Quintas es licenciada en Ciencias de la Información (periodismo) por la Universidad Complutense de Madrid y doctora en Publicidad y Relaciones Públicas por la Universidad de Vigo, en la que es docente desde 1996 en la Facultad de Ciencias Sociales y de la Comunicación. Ha sido coordinadora del programa de doctorado Gestión de la comunicación: Relaciones Públicas, Información y Publicidad durante tres bienios y secretaria de la Comisión Académica del Máster Investigación en Comunicación. Es miembro del grupo de investigación I+D ICOM (CS1) de la Universidad de Vigo y de la Sociedad Española de Periodística. Ha publicado artículos sobre periodismo en revistas como Latina, Razón y Palabra 
y Área Abierta; y dirigido proyectos de investigación financiados por la Cátedra Filgueira Valverde.

Montserrat Doval Avendaño es periodista (Universidad de Navarra, 1988) y doctora en Comunicación (Universidad de Vigo, 2009). Ejerció como periodista hasta 2009 en diversas publicaciones y gabinetes de comunicación. Desde 2004 es docente en la Facultad de Ciencias Sociales y de la Comunicación de la Universidad de Vigo. Es miembro del grupo de investigación I+D ICOM (CS1) de la Universidad de Vigo. Ha publicado en revistas como Latina y Estudios sobre el Mensaje Periodístico investigaciones centradas en la influencia de los medios sociales en el periodismo. 